\title{
EL DESTIERRO INFINITO DE BLANCO WHITE EN LA MIRADA DE JUAN GOYTISOLO
}

\author{
FERNANDO DURÁN LÓPEZ \\ Universidad de Cádiz
}

\section{RESUMEN}

En torno a los años 1970-1972 el novelista Juan Goytisolo publica varios estudios y traducciones sobre la obra de José María Blanco White, que suponen un momento clave en la recuperación de ese olvidado escritor para la moderna cultura española. La tesis formulada en el presente artículo es que la estrategia conscientemente identificadora que aplica Goytisolo sobre Blanco White, a fin de definir una tradición intelectual española a lo largo de los siglos marcada por el exilio y la disidencia, supone de hecho una deformación de la figura y el pensamiento del escritor sevillano. La recepción de Blanco White en España ha quedado, sin embargo, condicionada por esa lectura.

Palabras clave: Blanco White, Juan Goytisolo, exilios, disidencias.

\section{BLANCO WHITE'S INFINITE EXILE IN JUAN GOYTISOLO'S VIEW}

\begin{abstract}
In the years 1970-1972, the novelist Juan Goytisolo published several studies and translations on the work of José María Blanco White, which represent a key moment in the recovery of that forgotten writer for the modern Spanish culture. The argument made in this essay is that the consciously identifying strategy applied by Goytisolo on Blanco White, in order to define a Spanish intellectual tradition throughout the centuries, marked by exile and dissent, is in fact a deformation of the figure and thought of the writer from Seville. Blanco White's reception in Spain, however, has been conditioned by that reading.
\end{abstract}

Key words: Blanco White, Juan Goytisolo, exiles, dissidences 
En España [...] la gran vanidad de los escritores hace que todos busquen enseguida sentar cátedra y tener alumnos y no se dan cuenta que lo peor que le puede ocurrir a un escritor es tener discípulos. Lo importante de un escritor es tener una genealogía, forjarse una genealogía literaria. Este es el problema real y no tener discípulos que finalmente lo parodian (Juan Goytisolo, en Ruiz Lagos, 1991: 46-47).

\section{TRIBUS, POLÉMICAS, QUEJUMBRES}

En diciembre de 2004 se produjo una polémica periodística del diario El País con su crítico literario Ignacio Echevarría, algunas de cuyas ramificaciones resultan de interés para mi propósito. En septiembre Echevarría había reprobado públicamente al director adjunto de El País, Lluís Bassets, por desautorizar una reseña negativa suya a una obra de Bernardo Atxaga que le encargó el periódico; a la vez, denunciaba los intereses que contaminaban la labor de los críticos, puesto que la editorial que editaba al novelista vasco pertenece al grupo empresarial que publica el diario madrileño. El conflicto se saldó con la salida de Echevarría de la redacción y con un escrito de apoyo hacia él de un centenar de novelistas, críticos y editores, muchos de ellos colaboradores de El País. Poco más tarde, Juan Goytisolo terció en la polémica publicando en el mismo rotativo un artículo titulado «Cuatro años después» (28-I-2005) en el que atacaba acremente la hipocresía de Echevarría de impugnar lo que llevaba practicando catorce años desde esas páginas. Goytisolo recordaba otro artículo que escribió en enero de 2001, «Vamos a menos», fruto de su escándalo ante el premio Cervantes a Francisco Umbral, intensamente patrocinado por Echevarría. Allí había dejado escrito que ese premio probaba «la putrefacción de la vida literaria española, el triunfo del amiguismo pringoso y tribal, la existencia de fratrías, compinches y alhóndigas, la apoteosis grotesca del esperpento» ${ }^{1}$. Goytisolo citaba denuncias parecidas lanzadas mucho tiempo atrás por Cernuda. Ahora, en 2005, el novelista saldaba cuentas y se sorprendía del apoyo recibido por Echevarría en contraste con el silencio que envolvió su queja de 2001: "no se puede a estas alturas fingir inocencia de vestal y rasgarse las vestiduras cuando el conflicto con intereses "superiores" no afecta a otros, sino a uno mismo» ${ }^{2}$. De nuevo pedía releer los reproches de Cernuda al mundillo cultural español, a la vez que evocaba a Azaña. Echevarría respondió con una carta al director, que comenzaba de este modo:

Era de esperar que Juan Goytisolo hiciera su intervención estelar en el llamado caso Echevarría. Y era de esperar que lo hiciera como suele: sacándose en pro-

\footnotetext{
${ }^{1}$ GOYTISOLO, Juan. «Vamos a menos». El País, 10-I-2001.

2 Idem, «Cuatro años después». El País, 28-I-2005.
} 
cesión a sí mismo y citando de paso, mira por dónde, a Cernuda y a Azaña (la ocasión no daba esta vez para mentar a Américo Castro y a Blanco White). Da pereza refutar su gastada cantinela de quejumbres $[\ldots]^{3}$.

No estaría aquí hablando de este nimio rifirrafe si tan sólo fuera una pulla lanzada por un crítico contra un novelista enemigo; podemos encontrar manifestaciones en sentido parecido por parte de autores más ponderados. Veamos, por ejemplo, un artículo de Antonio Muñoz Molina en el suplemento Babelia del día 7-VI-2008 en El País. Se titula «El integrado, el apocalíptico» y está dedicado a comparar a Juan Goytisolo y a Carlos Ruiz Zafón a propósito de la comercialidad en la literatura contemporánea y a censurar el afán de ciertos escritores por elevar a ley universal literaria sus propias opciones.

Por eso cansan tanto los axiomas de los escritores, que cuando se repiten mucho revelan una herida que no quiere mostrarse. [...] Juan Goytisolo también se ve a sí mismo como un forastero en el mundo literario español, que le parece tan desolador como a Ruiz Zafón, pero por razones distintas: salvo él, Goytisolo, y alguno más, los escritores están entregados a la comercialidad más baja, a los caprichos del mercado, a la fabricación de groseros bestsellers [...]. Juan Goytisolo viene repitiendo desde hace tiempo las siguientes leyes de la literatura universal: los grandes escritores —el arcipreste de Hita, Blanco White, Jean Genet, el propio Goytisolo, por poner unos cuantos ejemplos- son heterodoxos y renegados que sufren persecución por su rebeldía, y que escriben obras tan rompedoras, tan arriesgadas, tan radicales, que no hay sitio para ellas en sociedades literarias regidas por el borreguismo y por la venalidad comercial, y que por lo tanto sólo son apreciadas plenamente por una minoría exquisita de lectores ${ }^{4}$.

Dejando de lado el fondo de estas polémicas, me interesa subrayar que ambos sarcásticos comentarios apuntan hacia ciertos rasgos de la actitud de Goytisolo como intelectual y de la genealogía que se ha forjado para respaldar tal actitud. Esos rasgos señalados vienen a concluir en dos afirmaciones sobre cuya base voy a desarrollar mi argumento: 1) que Blanco White es un tic de Juan Goytisolo; y 2) que el Blanco White actual es esencialmente el Blanco White de Juan Goytisolo. Y esos dos puntos creo que ilustran de forma muy efectiva la naturaleza de la recepción del escritor sevillano en la España más reciente, un tema nada baladí, sobre todo si convenimos con James D. Fernández en que «parecería que hablar de Blanco White es hablar también, necesariamente, de la recepción —o la no recepción- de Blanco White» (2005: 117). Así es, en efecto, y de ello, una vez más, voy a hablar.

\footnotetext{
${ }^{3}$ ECHEVARRÍA, Ignacio. «Respuesta a Juan Goytisolo». El País, 29-I-2005.

${ }^{4}$ MUÑOZ MOLINA, Antonio. «El integrado, el apocalíptico». El País-Babelia, 7-VI2008 .
} 


\section{Blanco White es un tiC de JuAn Goytisolo}

El hecho de partida es que José María Blanco White ha llegado a convertirse en un tic característico de Juan Goytisolo. No se trata tanto de una pose —ni tampoco una idea- como de un tic, es decir, una reacción que metafóricamente se ajusta bastante al sentido en que define el $D R A E$ esa palabra: «movimiento convulsivo, que se repite con frecuencia, producido por la contracción involuntaria de uno o varios músculos». Es, en efecto, un movimiento - en concreto, un movimiento ofensivo, de ataque-, es convulsivo y repetitivo, y en su periódica reproducción parece haber algo de automático, como un involuntario reflejo pavloviano ante el estímulo adecuado. Y todo tic, todo gesto repetido, es susceptible de convertirse en motivo de irrisión: como prueban las chanzas de Echevarría y Muñoz Molina, el recurso a la cita de Blanco White y de otros representantes de una presunta tradición española disidente se ha convertido en una caricatura inseparable ya de la figura misma de Goytisolo, que viene reiterando ese tic en textos escritos con regularidad desde aproximadamente 1970.

Hagamos un poco de historia. Goytisolo tomó conocimiento de la obra de Blanco White gracias, según él mismo dice, a Menéndez Pelayo, decodificando de forma inversa los juicios de valor del santanderino en sus Heterodoxos, como han hecho muchos otros en el siglo $\mathrm{XX}^{5}$ Sobre esta base, formó su interpretación de los escritos del sevillano a partir de las ediciones originales, entonces de acceso bastante difícil. Entre 1970-1972 divulgó varias lecturas y traducciones de Blanco en las revistas Triunfo y Cuadernos de Ruedo Ibérico —dos emblemáticas cabeceras del momento, una de Madrid y la otra del exilio republicano parisino-, así como en su propio proyecto, la revista Libre, que se publicó sin mucho éxito en París ${ }^{6}$. Final-

${ }^{5}$ Ya lo decía hábilmente Pere Gimferrer: «Un libro ortodoxo - la Historia de los heterodoxos españoles - ha obsesionado en la península ibérica a las mentes heterodoxas» (2000: 187). Véase también Durán López (2006).

${ }^{6}$ Sobre Goytisolo y estas revistas, véanse Forment (2000) y Sarría Buil (2002 y 2005). En Cuadernos de Ruedo Ibérico, aunque sin formar parte de su consejo de redacción, colaboró asiduamente surtiendo de trabajos propios y ajenos la sección literaria. La revista estaba muy tensionada por las divisiones del exilio, sobre todo las que rodeaban al PCE: frente a una tendencia hacia contenidos políticos directos y a un denso doctrinarismo, Goytisolo practicaba una crítica más indirecta a través de la creación literaria, basada en los mejores autores del momento, así como en la recuperación de una tradición histórica: «La idea era mostrar la actualidad de obras desconocidas o marginadas [...]. Publicaba lo que no se podía publicar en España mostrando que había una continuidad dentro de la discontinuidad de la cultura española, en la que hay siempre escritores arrinconados que se expresan de forma muy distinta a la literatura oficial» (en Sarría Buil, 2002). En tal sentido, Juan Goytisolo dio a conocer en estos Cuadernos, desde 1966, además de lo referido a Blanco White, varios artículos sobre la generación del 98, Cernuda, el Estebanillo González, Menéndez Pidal y Las Casas, el mundo erótico de María de Zayas. 
mente, en 1972, en una editorial de Buenos Aires por culpa de la censura franquista, dio a luz su antología de traducciones titulada Obra inglesa de Blanco White (reeditada en 1974 en España por Seix Barral, que la ha reimpreso varias veces), a la que precedía un extenso estudio preliminar que recogía y ampliaba lo ya publicado en revistas. Esta «Presentación crítica» se abría con una declaración de principios tan contundente como provocadora, que se grabó a fuego en la mente de los lectores:

La historia de la literatura española está por hacer: la actualmente al uso lleva la impronta inconfundible de nuestra sempiterna derecha. El destino póstumo del expatriado español José María Blanco White (1775-1841) podría servir de ilustración, en efecto, del funcionamiento de los mecanismos de represión y censura que determinan la escala de valores del país según la óptica de nuestros programadores culturales. ¿Qué sabe el lector español de hoy de él y su obra? (Goytisolo, 1982: 3).

Aunque el tono es apocalíptico y un tanto desmesurado, de acuerdo con el estilo del autor y con el hecho de que al filo de 1970 el cisma de las dos Españas estaba en un momento culminante, esa visión describe un hecho básicamente real. Eran, por otra parte, los mismos años en que escribía su trilogía narrativa de Álvaro Mendiola, donde destripaba a su manera el ser y la cultura de España, muy influido por sus lecturas de Américo Castro y de Blanco White: Señas de identidad (1966), Reivindicación del Conde Don Julián (1970) y Juan sin Tierra (1975).

Goytisolo no ha vuelto a aportar nada nuevo en su visión de Blanco White con posterioridad a 1972, pero sí la ha reiterado en infinidad de ocasiones. Por citar al menos un par de los abundantes ejemplos existentes, puede verse otro artículo de El País fechado en 1996 con el título de «Opiniómanos», donde tras sus habituales acusaciones contra los tribalismos del mundo literario español, acaba con su no menos habitual retahíla de autoridades: «Releamos a Blanco White, Clarín y Cernuda y encontraremos la llave de muchos enigmas. Como decía Larra a la España de su tiempo, “ipara usted no pasan días!”. Para la nuestra, tampoco. Resignémonos pues: somos nosotros los que pasamos» ${ }^{7}$. Y también en El País insistió de nuevo el 5-VI-2001 con otro texto llamado «Blanco White y la desmemoria española», que más adelante se reeditó como primer trabajo del volumen colectivo José María Blanco White: crítica y exilio ${ }^{8}$.

La clave en ese vínculo intertemporal se resume en dos palabras, que hemos de tener muy en cuenta en todo momento: identificación y, por medio de ella, autolegitimación. La relectura que hace Goytisolo de Blanco Whi-

\footnotetext{
${ }^{7}$ GOYTISOLO, Juan. «Opiniómanos». El País, 9-IV-1996.

${ }^{8}$ «Un escritor marginado: Blanco White y la desmemoria española» (Goytisolo, 2005). Era el resultado de un seminario celebrado en Nueva York en 2001 donde el novelista barcelonés intervino en lugar destacado.
} 
te opera un proceso identificador de su experiencia con la de él. De hecho, si alguien lee la «Presentación crítica» comprobará que Goytisolo, más que realizar una exposición y comentario crítico de las ideas del autor, tiende a establecer paralelismos y comparaciones con la España actual y con su propia experiencia personal: «la pluma de Blanco obra el milagro de enfrentar al lector con su propia vida: para quien ha conocido la España de los años cuarenta, numerosos pasajes de sus memorias traen irresistiblemente a las mientes una serie de experiencias y traumas que hubiese preferido olvidar para siempre»(Goytisolo, 1982: 17); «las dudas, angustias, temores que abruman la conciencia de Blanco nos han abrumado también a nosotros» (17); «...recibimos una formación similar a la suya y lidiamos con las mismas dificultades y escrúpulos al romper con ella» (21); «el eco de una emoción íntima que nos encara de golpe a los fantasmas de nuestra propia vida» (21); «su experiencia [...] cifra en sí la historia secreta de miles y miles de sus paisanos [...], historia de ayer, de hoy y, mucho me temo, de mañana» (21); y un largo etcétera de comentarios similares que jalonan cada página. El novelista, por otra parte, nunca ha ocultado tal hecho y el pasaje más habitualmente citado de su «Presentación crítica» de 1972 es el que la cierra:

Acabo ya y sólo ahora advierto que al hablar de Blanco White no he cesado de hablar de mí mismo. Si algún lector me lo echa en cara y me acusa de haber arrimado el ascua a mi sardina, no tendré más remedio que admitir que la he asado por completo. Pero añadiré en mi descargo que resulta difícil, a quien tan poco identificado se siente con los valores oficiales y patrios, calar en una obra virulenta e insólita [...] sin caer en la tentación de compenetrarse con ella y asumirla, por decirlo así, como resultado de su propia experiencia (Goytisolo, 1982: 98).

Desde entonces se ha mantenido en la misma convicción de que existe una comunidad moral e intelectual entre él y Blanco White. Esa identificación ha calado en la mayor parte de los críticos y lectores que se han interesado por ese vínculo y que han conocido a Blanco a través de Goytisolo. En ese sentido, puede decirse que ha sido un éxito y que el novelista ha conseguido fijar en la mentalidad colectiva el paralelismo entre los exilios de Blanco White, de Cernuda y el suyo propio. Así, Pere Gimferrer, en un artículo que viene a ser una reseña de la Obra inglesa, suscribe esa identificación (sólo introduce algunas salvedades, a las que me referiré después):

Para Juan Goytisolo, la figura de Blanco White se inscribe en una constelación más amplia de españoles expatriados y excluidos por su país, y [...] desarrolla un paralelismo que se hace cada vez más explícito entre el destino del autor de las Letters from Spain, el de Cernuda y, por último, el suyo propio. En este sentido, puede decirse que para Goytisolo resulta ser Blanco una imagen anticipada de sí mismo, o, por mejor decirlo, la encarnación de un mito del mundo moral: el mismo que aparece asumido por el protagonista múltiple de Reivindicación del conde 
don Julián o por la irreconocible voz que suscita el discurso de Juan sin Tierra. [...] Esta interpretación, aunque no prescinda de la subjetividad del escritor [...], no puede calificarse, ciertamente, de desnaturalizadora o abusiva: los escritos de Blanco la reclaman (Gimferrer, 2000: 189-190).

Las aproximaciones críticas sobre este punto, con mayor o menor distanciamiento, parten de tal idea. Algunas de ellas, siguiendo de cerca la estela interpretativa trazada por la voz de Goytisolo, presentan de manera positiva o cautamente neutral el canibalismo del catalán hacia el sevillano9. Así, Alison Ribeiro de Menezes (2007) define estas maniobras intertextuales como una suerte de «ventriloquia», en que Goytisolo opera como ventrílocuo de los autores de su anticanon heterodoxo, haciéndoles hablar con su propia voz. Pero, si bien esto parece sugerir una idea de manipulación, a continuación se afirma que «this is not a silencing of the original and of origins, but raher a ventriloquism where the sources are evident and the dummy, as it were, can speak back» (2007: 81). En verdad, no se sabe bien de qué modo los muñecos podrían a su vez tomar la palabra en este diálogo, quizá por eso la autora acude a continuación a una más elegante noción, la heteroglosia de Bajtín: «in this, it is more akin to a Bakhtinian notion of heteroglossia in which the occupation of the voice of the other is a form of self-creation -in short, an autobiographical act- but one which does not in the process silence or destroy the other» (2007: 81). Por su parte, Gonzalo Navajas (2001) recurre a la consabida y elástica idea de intertextualidad para interpretar esta identificación como «componente interdialógico» y «dimensión ética», en un estudio en el que quiere mostrar que el proceso de lectura crítica que efectúa el barcelonés sobre sus precursores está movido por «el propósito crítico de unas formas ideológicas predominantes». Sería una forma de respuesta alternativa al actual paradigma posmoderno de «indiscriminación intertextual de la estética actual» y su «indefinición axiológica». Frente a una intertextualidad basada en la cita múltiple e indiscriminada, en la confusión y reciclaje de los órdenes jerárquicos convencionales, su forma de diálogo intertextual sería una vía de disidencia crítica.

En lugar de un abanico de textos elegidos indiscriminadamente que produce la visión ecléctica e indefinida de la estética finisecular, Goytisolo opta por textos que vehiculan y proyectan su visión particular de la literatura con relación a la

${ }^{9} \mathrm{El}$ concepto de canibalismo es de Loureiro: «Blanco White is not merely translated by Goytisolo but is appropriated in an act of cannibalism, transformed into Goytisolo's flesh, a re-incarnation» (1998: 51). También lo usa, de forma abiertamente laudatoria, Eduardo Subirats: «Goytisolo [...] canibalizó la crítica de Blanco White, estableció una estrecha identificación con su destino social e intelectual, y construyó una ruptura con las tradiciones dominantes del tradicionalismo español enclaustrado en la cultura franquista a partir de la violenta ruptura con la cultura, la historia y la lengua españolas expuesta por Blanco White» (2005: 15). 


\begin{abstract}
circunstancia nacional. Su diálogo intertextual con Blanco White y Cernuda es un ejemplo. Ambas figuras aparecen como Doppelgängers del propio Goytisolo. El yo personal se fragmenta y multiplica en otros yos. En lugar del «autómaton escolástico y erudito» que, según Bourdieu, caracteriza la investigación académica, Goytisolo opta por lecturas que potencian la imbricación de los elementos personales en los textos comentados. [...] Blanco y Cernuda son prolongaciones del yo de Goytisolo y, a su vez, en su lectura de ellos, Goytisolo se convierte en modos de manifestación del yo de los autores elegidos. El diálogo intertextual afecta a todos los participantes en él en un intercambio que rompe las fronteras espacio-temporales. Blanco es Goytisolo y Goytisolo es Blanco (Navajas, 2001).
\end{abstract}

Pero esta recurrente metáfora que muestra la relación intertextual como diálogo, no representa en realidad sino un soliloquio de Juan Goytisolo, una relectura y apropiación — tan legítima como unidireccional- de aquellos autores que él ha proclamado como sus precursores. Si la escritura de Blanco White se ha convertido en un mero «acto autobiográfico» de Goytisolo, si las palabras de aquel son manifestación de los «elementos personales» de este, ¿en qué momento y en qué modo puede hablar Blanco por sí mismo? El esfuerzo del novelista para echarse sobre los hombros una genealogía literaria se ha cumplido exitosamente y, desde 1970, los escritos de Goytisolo han conseguido establecer una identidad transtemporal entre él y Blanco White como otro rasgo de su obra y personalidad. Esta lectura retrospectiva es, obviamente, un derecho de todo escritor que busca sus fuentes. No tendría mayor importancia si la vemos desde el punto de vista de nuestro conocimiento del creador Juan Goytisolo, pero en cambio - y ese es el punto que me interesa- desde la perspectiva de la recuperación e interpretación de la obra de Blanco White, esa ventriloquia ha deformado su voz.

\title{
3. El Blanco White actual es el Blanco White de Goytisolo
}

Así pues, mi segunda afirmación de partida es que la identidad establecida entre el novelista y su presunto precursor no sólo ha definido una tradición para Goytisolo, proporcionándole un rasgo clave de su personalidad literaria - el de continuador de una larga estirpe de españoles golpeados por el casticismo y la intolerancia hispánicas-, sino que también ha definido la imagen y la interpretación de Blanco en esos mismos términos. El Blanco White reintroducido en la cultura española del último tercio del XX es en lo esencial el creado por Goytisolo para dotarse a sí mismo de una tradición intelectual y, por así decirlo, para «vender» esa tradición a la España actual como remedio frente al secular estancamiento moral, cultural y mental en que, según el novelista, sigue inmersa la vida nacional. Es un mimetismo a la inversa, por el cual el autor posterior no se mimetiza con el anterior, sino que hace a este mimetizarse con él. 
En realidad, no tendría por qué haber sido así. Simultáneamente a los trabajos del catalán sobre Blanco White, aparecían en España otras dos publicaciones esenciales: la Antología de obras en español de Vicente Llorens en la editorial Labor en 1971 y las Cartas de España traducidas por Antonio Garnica en la colección de bolsillo de Alianza Editorial en 1972, que desde entonces se han reeditado tres veces en esa colección y dos en otras editoriales. Así pues, el periodo 1970-1972 es el momento clave en el redescubrimiento de Blanco White. Es importante destacar que estos proyectos editoriales son paralelos e independientes entre sí, aunque es muy probable que los esfuerzos divulgatorios de Goytisolo les hayan facilitado el camino a la hora de suscitar el interés de editoriales comerciales de gran difusión. Ahora bien, la coincidencia cronológica de los tres libros hace pensar que la «vuelta a casa» de Blanco White pudiera haberse realizado incluso sin el impulso que le dio Goytisolo - aunque sin duda hubiera sido más limitada y académica- y que, además, podría haber suscitado otras lecturas diferentes. Pero eso es ficción: el hecho es que la línea intelectual que ha otorgado a Blanco un valor de actualidad ante el gran público es, en grandísima proporción, deudora del novelista, cuyos ecos resuenan consciente o inconscientemente cada vez que se habla del sevillano, a pesar de que el Blanco White de los académicos es mucho más variado, complejo y real ${ }^{10}$.

Un trazo decisivo de ese Blanco White es lo que parafraseando la «revolución permanente» de Trotsky podríamos denominar la «recuperación permanente», es decir, la idea que Goytisolo viene sosteniendo desde hace treinta años de que Blanco White - y toda la tradición y contenidos que él asocia de inmediato a ese nombre- está aún por recuperar, de que la cultura oficial española sigue considerándolo un traidor y un autor maldito, de que España apenas ha salido en ese punto de la parálisis intelectual suscitada ininterrumpidamente por el casticismo hispánico desde la Reconquista hasta Franco... y más allá. La tesis de Goytisolo es que Blanco White sigue estando en la cultura española donde estaba en 1970. Así, en un coloquio celebrado en Buenos Aires en 1989, Roberto Yahni le pregunta al barcelonés qué cambiaría en su presentación crítica de Blanco White si tuviera que reescribirla ahora:

Tal vez la escribiría con menos violencia, porque, para bien, la historia de España ha variado en los últimos años. La redacté en un momento en que el cambio era posible, pero no se vislumbraba de una forma cercana. El análisis que Blanco hacía de la sociedad de su tiempo se adaptaba perfectamente a la sociedad espa-

\footnotetext{
${ }^{10}$ Un buen ejemplo de la pervivencia y profundidad de la imagen goytisoliana de Blanco es la obra de Eduardo Subirats, que prácticamente suscribe punto por punto su visión. El seminario que coordinó en Nueva York en junio de 2001 y que tuvo a Goytisolo como invitado principal se publicó en 2005 con una introducción de Subirats que es todo un compendio de la citada visión, a pesar de que las colaboraciones de los autores recogidos en el volumen caminan en direcciones muy distintas y más matizadas.
} 
ñola que yo conocía pero, dicho esto, Blanco sigue manteniendo una vigencia enorme (en Ruiz Lagos, 1991: 45).

Y seguidamente explaya una vez más su escándalo por el olvido en que sigue sumido Blanco White, afirma que «el libelo de traidor sigue pesando sobre él», que a pesar de su traducción de 1972 «sigue pesando sobre él un silencio sepulcral», se lamenta de que nunca se le cite en los editoriales y colaboraciones de El País, etc. (en Ruiz Lagos, 1991: 45). De hecho, la cauta y no poco razonable afirmación inicial de que España ha mejorado, queda de inmediato convertida en un gesto retórico porque su comentario subsiguiente retrocede al punto inicial:

Después de doce o trece años de democracia nos encontramos con estas incapacidades culturales, con estas censuras internas. Es decir, que han cambiado muchas cosas y otras en absoluto y no es por culpa de un poder, no hay ninguna censura que lo vede, no hay ningún gobierno que lo prohíba, es una incapacidad, yo creo, de ver lúcidamente nuestra propia cultura (en Ruiz Lagos, 1991: 46).

De hecho, conforme pasan más años, los matices positivos sobre la evolución de la sociedad española no se refuerzan, sino que parecen ir involucionando. En otra entrevista en $A B C$ de abril de 2007 Goytisolo declara la total vigencia de Blanco White cuando el periodista le formula una pregunta que no es más que un reflejo de la evidente expectativa de respuesta creada por el propio novelista a lo largo de su trayectoria:

Pregunta: Usted es un gran estudioso de un sevillano ilustre: José María Blanco White, al que ha traducido su obra escrita en inglés. ¿No cree que no hemos avanzado mucho desde entonces?

Respuesta: Es increíble que me diga esto porque lo he vuelto a releer hace poco y las cosas que dice sobre la intolerancia religiosa, las tradiciones, etc., tienen una actualidad enorme. Cuando empecé a traducirlo, me parecía que no lo estaba escribiendo él, sino yo. La identificación era total, a pesar del enorme tiempo transcurrido ${ }^{11}$.

Pero quizá tenga mayor interés otra entrevista anterior, de 1999, en la que hablaba del Quinto Centenario y ponía como ejemplo de lo que llama «las constantes de la historia española» el hecho de que él había propuesto a una universidad organizar un curso sobre Blanco White para dar a conocer a los hispanoamericanos que también hubo españoles partidarios de su independencia. Su propuesta no tuvo acogida, lo que le motiva la siguiente reflexión, ya presente en términos análogos en la «Presentación» de 1972:

En cualquier otro país, supongamos en Francia, estarían encantados de hablar de un escritor, de cara a los países colonizados, que demostrara la existencia de intelectuales que estuvieran a favor de la independencia, que tuvieran esa lucidez y

11 ÁLVAREZ SEVILLA, Jesús. «Juan Goytisolo: "La mayoría de las novelas sobre la Guerra Civil caerán en el olvido"». $A B C, 15-I V-2007$. 
esa honestidad. En España sigue siendo un traidor. [...] Se ve a la hora de la verdad que, en el momento de la guerra, al único intelectual español que tomó partido públicamente por la independencia, lo siguen marginando. Son las constantes de la historia española (en Eilenberger, 1999).

Y en un artículo de El País de 2001 volvió a contar esa misma historia con más detalles, para concluir una vez más que

el vituperado defensor de aquellos [los pueblos hispanoamericanos] en su parto sangriento permanece aún en cuarentena un siglo y tres cuartos después de los hechos. En corto, las conmemoraciones del Quinto Centenario no incluyeron la menor referencia a Blanco White y todo se redujo a un pomposo concurso de flatus voci y gesticulación para la galería ${ }^{12}$.

Sin embargo, difícilmente puede ignorar Goytisolo - ya que es un asiduo seguidor de Blanco White y un observador crítico de su recepción en España- que justo con motivo del Quinto Centenario, en una colección financiada con los fondos de esa conmemoración y dirigida al público hispanohablante de ambos hemisferios, Manuel Moreno Alonso publicó en 1993 en el Instituto de Cooperación Iberoamericana un volumen titulado Conversaciones americanas y otros escritos sobre España y sus Indias, donde se recogen todos los textos fundamentales de Blanco White sobre ese asunto. ¿Puede entonces decirse que las celebraciones del Quinto Centenario marginaron a este autor por seguir considerándolo un traidor al ideal nacionalista español?

Desde 1970 se han publicado una buena cantidad de libros sobre Blanco White, monografías, ediciones y traducciones de sus obras, etc. Antes que Goytisolo, ya Vicente Llorens había trabajado a fondo para recuperar la figura del escritor sevillano, aunque su labor sólo tuvo eco - fructífero, pero retardado, según los ritmos propios del conocimiento científico- en el entorno académico. Paralelamente a la popularización realizada por Goytisolo se desarrolló la labor traductora, editora e interpretadora más sistemática de Llorens, Garnica, Moreno Alonso, Pons, Murphy, Viñao... Varias de sus obras clave han conocido numerosas reimpresiones y han aparecido en colecciones comerciales como el Libro de Bolsillo de Alianza Editorial. Aunque todo es mejorable, pocos o ninguno de los escritores de la generación de principios del XIX están tan bien editados, tan accesibles al gran público o han sido tan estudiados como Blanco. Si bien esos otros escritores partían de una posición más ventajosa y de un reconocimiento más antiguo, ninguno tiene hoy acceso a un público diferente al más especializado. Se ha dado el raro caso de que una obra tan poco vendible como Vargas - que ni siquiera es seguro que sea de Blanco- conociera dos traducciones distintas en España el mismo año.

\footnotetext{
12 «Blanco White y la desmemoria española». El País, 5-VI-2001.
} 
Y sin embargo Goytisolo ha seguido estos treinta años recitando el mismo mantra del olvido y marginación con que este país cainita condena a sus disidentes y omitiendo la evidencia de que, gracias sobre todo a sus desvelos, ese olvido ya no era tal. Es como si su éxito le desarmara el argumento, porque en realidad le importara más el propio argumento que el objeto concreto sobre el que argumenta. Goytisolo tampoco parece acusar el impacto de la investigación y la edición que se ha amontonado sobre Blanco White, ni parece que haya servido para modificar un ápice de sus ideas iniciales. Es difícil saber qué recuperación sería suficiente para superar la marginación de la que habla Goytisolo, pero acaso no es España, sino Goytisolo, el que está detenido en 1970. Esto resulta tan evidente que ha motivado incluso reacciones molestas por parte de algunos estudiosos. Una vez más en el El País Goytisolo publicó una nueva variante — no muy variada- sobre el mismo tema en su artículo de 2001 «Blanco White y la desmemoria española» ${ }^{13}$, lo cual motivó que José Luis Abellán escribiera una réplica en la sección de «Cartas al director» del mismo rotativo el 27VI-2001:

[...] insiste una vez más — creo que es la enésima vez que lo hace- en el desconocimiento que tenemos en España de la figura de José María Blanco White, remitiéndose todavía a la atención que le prestó en el siglo pasado Menéndez Pelayo, y después, en el nuestro, Méndez Bejarano y Vicente Llorens, desconociendo que yo mismo le he prestado una atención muy importante en mi obra Historia crítica del pensamiento español (tomo IV, 1984). En esta obra dedico a Blanco White casi 40 páginas, insertándole en el Movimiento Liberal y Romántico de nuestra tradición intelectual. Tengo tanto interés como el señor Goytisolo por la recuperación de este viejo liberal proscrito entre nosotros, pero, si no nos leemos entre nosotros, mal podrá hacerse esa recuperación.

El objeto principal de esta carta no es tanto rectificar al señor Goytisolo como llamar la atención de los lectores, pues sé que tiene muchos y le siguen apasionadamente, con lo cual dan por hecho que de Blanco White no se ocupa nadie en España, lo cual, evidentemente, no es cierto. Además de lo escrito por mí, también hay que contar con la atención que le han dedicado los profesores Antonio Garnica, Manuel Alonso Montero [sic] y el propio Goytisolo [...].

Ahora bien, esta «recuperación permanente» del sevillano por parte de Goytisolo no es algo que haya que atribuir a desconocimiento; su actitud dice cosas más profundas sobre la estrategia identificadora del novelista. La distancia entre España y el solitario disidente que clama en el desierto -Blanco, pero también Goytisolo - ha de mantenerse, a riesgo de que, si no, esa disidencia pierda sentido y deje de proporcionar una identidad a quien la ejerce: la de exiliado. Pero un exiliado sólo lo es cuando está en el exilio: si Blanco volviera a casa, también tendría que hacerlo Juan Goytisolo, cuya identidad reside por voluntad propia en que «su figura re-

\footnotetext{
${ }^{13}$ El País, 5-VI-2001.
} 
presenta hoy al eterno exiliado, ciudadano del tiempo y de la memoria, que ha conseguido saldar la amargura del exilio en una única pertenencia, la del idioma» (Sarría Buil, 2002). Por eso, por la necesidad de asimilar la experiencia de Blanco con la suya propia — que no al contrario-, el sevillano está condenado a vagar por el limbo de los justos hasta el final de los tiempos.

$\mathrm{Y}$, por otra parte, la reiteración de Goytisolo de que la crítica de España articulada por este eterno judío errante sigue siendo válida y necesaria, explica también las características esenciales del Blanco White reconstruido por Goytisolo entre 1970-1972. Es certera la observación de Luis Fernández Cifuentes, en un ensayo publicado en 2005, al glosar la idea goytisoliana de la vigencia de Blanco:

Esta vigencia de Blanco suscita otra perturbadora paradoja, tal vez una contradicción. Se diría que la «vuelta a casa» de Blanco es también un síntoma del estado de cosas del país: si se puede recuperar a Blanco, será porque en estos últimos doscientos años el país ha mejorado lo suficiente; España, su «casa», se ha abierto, se ha modernizado... etc. Sin embargo, dos de los más lúcidos y comprometidos promotores de esta recuperación, Juan Goytisolo y Eduardo Subirats [...], alegan explícitamente que la importancia de recuperar a Blanco se debe sobre todo a que nada ha cambiado desde entonces, es decir, que la «mentalidad inquisitorial española» se comporta todavía como en su tiempo. En principio parece que sólo caben dos formas de resolver la contradicción: o bien la recuperación es una forma de domesticación, de neutralización, o bien la recuperación supone algún grado de deformación o «tergiversación» (Fernández Cifuentes, 2005: 26).

Fernández Cifuentes no contesta abiertamente a la opción que plantea, pero mi hipótesis es que lo que ocurre es lo segundo: que la recuperación de Blanco White por Goytisolo y otros que le han seguido es una recuperación deformante. Y voy a dedicar el resto de estas reflexiones a concretar en qué sentido creo que el Blanco White de Goytisolo está tergiversado e incompleto. La matriz de esa deformación, a mi juicio, reside en la religión.

\section{La Religión de Blanco White vs. LA SEXualidad de Goytisolo}

El punto central en el que la lectura de Juan Goytisolo ha distorsionado la comprensión de Blanco White atañe, en efecto, a la dimensión religiosa de su vida y de su obra. En su citado ensayo Fernández Cifuentes ya señalaba ese punto débil:

Este proceso de recuperación de Blanco, que he reducido a dos corpus - el corpus autobiográfico y el corpus crítico-, deja en cierto modo excluida toda un área de la producción de Blanco que bien pudiera ser la más voluminosa, la más influyente y la más característica: me refiero a sus escritos religiosos, que aumentaron sobre todo al final de su vida. [...] Al mismo tiempo, como señalaba John Hamilton Thom, sus escritos autobiográficos no eran más que «la historia reli- 
giosa de un individuo» [...] y su crítica de la nación raramente aparece disociada de la función política y social de la Iglesia en España. [...] Se produce así una de las paradojas que caracterizan a Blanco y su recuperación: el componente religioso es fundamental tanto en la configuración de la identidad de Blanco como en su crítica de la nación, pero su obra estrictamente religiosa parece ser, al mismo tiempo, al menos en nuestra coyuntura histórica y cultural, lo más difícilmente recuperable de sus escritos, lo menos vigente (Fernández Cifuentes, 2005: 26) ${ }^{14}$.

Lo que Fernández Cifuentes no hace explícito es que esa forma de parcelar a Blanco White, de enmarcarlo en un conflicto exclusivamente nacional —de la nación española, claro está- que obvia su carácter cristiano y su integración en la sociedad británica, aunque vengan ya en parte de Vicente Llorens, tienen como principal responsable y divulgador a Juan Goytisolo $^{15}$. En la lectura del barcelonés la obra religiosa de Blanco estorba a lo que realmente le interesa: la crítica de España. Por ello Goytisolo ignora o malinterpreta en sus análisis la intensa y sincera espiritualidad cristiana que preside la trayectoria personal del sevillano desde aproximadamente 1812. Es el único modo de conseguir una identificación más completa con su propia experiencia como autoexiliado y disidente de la España franquista. Para que Blanco sea un precursor de Goytisolo, su relación con el catolicismo español, con la moral cristiana y con el hecho religioso han de ser equivalentes.

Un Blanco White cristiano - de hecho, un propagandista de la fe, casi un profeta - no sirve como modelo para una ruptura con la España castiza como la que efectuaron los exiliados republicanos y los disidentes antifranquistas del siglo XX, que en su mayor parte actúan - como los libera-

${ }^{14}$ Esto ya había sido señalado por Ángel G. Loureiro: «By making Blanco a precursor, Goytisolo commits a misreading that necessarily ignores the difference that separate the two authors. Blanco's concerns are almost exclusively religious, and his focus in on finding a religion that agrees with his rational philosophy. Goytisolo defines his self through a complete rejection of religion, fatherland, genealogy, language, and conventional sexuality» (1998: 52). Yo mismo dediqué muchas páginas a contradecir esta mutilación de la dimensión religiosa de Blanco White, que no es exclusiva de Goytisolo (cf. Durán López, 2005). Alison Ribeiro de Menezes, por su parte, ilustra este punto concreto con ejemplos de la selección de textos seleccionados por Goytisolo en la Obra inglesa, mostrando que el catalán, tras traducir el pasaje de Blanco que relata de forma muy negativa los «ejercicios espirituales» de su niñez sevillana, corta el texto para no incluir el comentario del autor en defensa del «verdadero cristianismo». «One can only speculate that this may be because this aspect of the writer is of less interest to Goytisolo» (Ribeiro, 2007: 88).

${ }^{15}$ Llorens, también exiliado y también tendente a la mitificación de una estirpe transtemporal de exiliados españoles, no suele estar interesado en los aspectos religiosos de Blanco y no siempre los comprende correctamente, pero sus trabajos son sectoriales y se ocupa de lo que le interesa sin prejuzgar en exceso las partes de su autor que no le interesan tanto. Lo mismo cabe decir de la mayor parte de los otros recientes estudiosos de Blanco atraídos por su dimensión política y su crítica de España, como Moreno Alonso y Pons, que también obvian al Blanco teólogo y espiritual, a veces de forma desdeñosa. No es el caso de Martin Murphy ni tampoco el de Antonio Garnica. 
les del XIX con los que el Blanco White inglés no quiso confundirsedesde una perspectiva no sólo anticlerical o tolerantista, sino generalmente atea o irreligiosa. Dicho de forma aún más rotunda: no se quiere ver un Blanco White cristiano porque, según la experiencia política y cultural de la España moderna — como el mismo Blanco lamentó amargamente-, la noción de un disidente cristiano parece una contradicción in terminis, incluso si se hace el esfuerzo intelectual — desusado entre españoles- de distinguir cristianismo de catolicismo. Ese esfuerzo sí hubiera sido posible durante buena parte del siglo XIX, donde hay una activa corriente de disidencia progresista que se efectúa dentro de los cauces religiosos de una espiritualidad no muy lejana a la de Blanco White, a la de la rama racionalista de la teología protestante alemana, o a la de los unitarios y trascendentalistas ingleses y norteamericanos. Las ideas de los krausistas y los católicos liberales como Fernando de Castro - y muchos otros hasta el regeneracionismo finisecular - sí podrían haber entroncado con una línea que, como la del sevillano, fuese capaz de ofrecer un decidido reformismo político, social y cultural desde bases espirituales cristianas de carácter racionalista y antiautoritario. Pero en esos años, en los que la influencia de Blanco White pudiera haber sido más fecunda, este estaba completamente olvidado en España y estigmatizado como traidor. En cambio, la corriente principal del progresismo español del siglo XX es indiferente u hostil a la espiritualidad. Los precursores que Goytisolo o los exiliados republicanos buscan no son ni pueden ser reformistas religiosos, de ahí que Blanco sólo pueda servirles como referente si se mutila su dimensión espiritual.

De esta exclusión o incomprensión del hecho religioso provienen, según mi modo de ver, todos los juicios erróneos que ha amontonado sobre Blanco White la recuperación propiciada por Goytisolo. Al no querer ver un Blanco White cristiano, al no querer indagar en la coherencia interna de la evolución espiritual del sevillano en Inglaterra, ni seguir el rastro de sus libros y sus actos en el terreno religioso, el resultado es un abanico de incomprensiones encadenadas que podemos reducir a tres puntos: 1) ver en Blanco White una ruptura con la moral cristiana y no sólo con la Iglesia católica; 2) ver en él un existencialista o un posmoderno, atormentado por la duda y la incapacidad de encontrar verdades permanentes; y 3) ver en él un pensamiento esencialmente negativo, crítico.

\section{1) Blanco White y la moral cristiana}

No comprender que Blanco rompió con la Iglesia católica - y luego con la anglicana-, pero no con el cristianismo, hace que se confunda en su vida y en su obra la crítica contra el catolicismo y el dogmatismo con una crítica contra la moral cristiana que jamás hizo. Si leemos algunas de 
las palabras elogiosas de Eduardo Subirats hacia la relectura goytisoliana de Blanco, apreciaremos hasta qué punto se ha asentado esta idea: «Goytisolo reedita y amplía las críticas a la moral y las supersticiones dogmáticas, al lenguaje y las costumbres de la cultura eclesiástica española en una retahíla de rudos sarcasmos que abarcan desde la miseria sexual hasta los prejuicios racistas de los nacionalismos católicos españoles» (2005: 16). Eso es cierto en el caso de Goytisolo, pero es más arriesgado decir que tal actitud «reedita y amplía» el ejemplo de Blanco White si en la lista de críticas se cuela de rondón una presunta ruptura con «la moral», junto a otras rupturas que sí están bien fundadas. Blanco White no sólo no efectúa tal ruptura, sino que, a lo largo de su vida, al ir cuestionando cada vez más la teología dogmática, acaba por reducir la esencia de la religión justamente a la moral, creyendo que la principal prueba de la existencia de Dios es que en el ser humano existe una conciencia moral innata e universal, introducida por Dios en el alma a modo de guía interior, tal como habían sostenido los antiguos estoicos y como creían en su tiempo los cuáqueros. En resumen, en el largo periplo teológico que experimenta desde su crisis de fe hacia 1800 hasta su muerte en 1841 Blanco White cambió varias veces de obediencia religiosa, para finalmente acabar profesando un cristianismo racionalista con muy pocos elementos metafísicos y dogmáticos, pero en todo ese tiempo profesó ininterrumpidamente una firme creencia en el valor universal e incuestionable de los valores morales del cristianismo.

En cambio, la ruptura que propone Goytisolo con la tradición de la España castiza e intolerante es ante todo una ruptura con la moral cristiana, con el puritanismo. En ella hay un notable componente sexual, una liberación del cuerpo que acompaña la liberación del alma, o, más aún, que de hecho constituye en sí misma una liberación del alma. Pero es insólito que Goytisolo llegara a creer que Blanco White pudiera servirle de ejemplo o precursor en semejante ruptura, porque el puritanismo sexual y moral del sevillano es indiscutible. De hecho, para cualquier lector de Blanco resulta evidente la profunda carga de angustia que acompaña a lo largo de su vida la relación con su cuerpo, relación marcada por la somatización de sus crisis morales, por la culpabilidad inducida por el impulso sexual reprimido y por la victimización provocada por sus continuas enfermedades y flaquezas físicas ${ }^{16}$. Nunca llegó a plantearse que la libertad sexual o el disfrute de su carnalidad fueran objetivos lícitos del hombre, salvo en el punto menor de acabar repudiando con los protestantes un celibato sacerdotal católico que, por otra parte, él nunca dejó de practicar. Ya lo vio así perspicazmente Pere Gimferrer (2000), quien, a pesar de aceptar la mimética identificación de Goytisolo con Blanco, señalaba que la religión

${ }^{16}$ Sobre esto véase Urda Anguita (2007). 
y el erotismo - o por mejor decir, el ateísmo y la sexualidad transgresora- son dos elementos de separación entre ambos escritores. Dicho de otro modo, que para operar esa mitificación autojustificatoria de Blanco White, Goytisolo le atribuye unas heterodoxias de las que el sevillano hubiera sin duda abominado:

Blanco, sin embargo, no es Sade: tal es su límite. Su crítica del catolicismo primero y del anglicanismo después no llegó a desembocar en crítica del hecho religioso mismo; su crítica del celibato eclesiástico no llegó a generalizarse en crítica de la moral sexual del cristianismo. De hecho, una ruptura tal no se hará patente en la literatura en lengua castellana, en tanto que tema central de una obra, hasta Reivindicación del conde don Julián, de Goytisolo (Gimferrer, 2000: 191).

\section{2) Blanco White y la duda}

Analizando la manera angustiosa de autoexamen y continua reescritura de sus textos autobiográficos que caracterizan a Blanco White, Ángel Loureiro concluye que «this apostate, however, will never find a way to return home because, by following the logic of the passions that he proposes, his reading will only be the first in an endless chain of readings that will correct one another. [...] In order to counter the univocal reading of the church, Blanco at once unleashes and tries to contain the terror of that infinite reading» (1998: 46). Que Blanco White se somete a sí mismo a una permanente y exigente reinterpretación no se puede negar. Sí es más discutible el alcance que se quiere atribuir a ese examen de conciencia, porque cambia mucho la cosa si el largo camino tiene un destino final o si el vagabundaje moral del sevillano es un viaje a ninguna parte. En otros lugares de su artículo, Loureiro hace matizaciones que modifican mucho lo antes dicho: «this extreme rationalism is Blanco's final philosophy, and it is one that allows him to reconcile his philosophical ideas with his Christian faith. It could be argued that such rationalism is present in Blanco almost from the beginning» (47); «it should be noted, however, that Blanco does not change substantially once he becomes a Unitarian, and the reassessment of his life often emphasizes the extent to which his current ideas were already present in the past» (54).

Así pues, se trata de un pensador en ruta hacia un destino filosófico, que finalmente encuentra. Pero la mayor parte de quienes se han acercado a esta cuestión no han considerado preciso introducir tales matices. Tanto el católico conservador Menéndez Pelayo como los anglicanos ortodoxos que comentaron con escándalo el abandono de la Iglesia de Inglaterra por Blanco White para hacerse unitario, han preferido verlo como una suerte de enfermo incapaz de fijar una convicción, condenado a un peregrinaje incesante de doctrina en doctrina. En todas estas visiones, el camino del sevillano —católico, luego ateo, luego convertido de nuevo al cristianismo 
como anglicano, luego activista anticatólico influido por la rama evangelista del anglicanismo, luego girado hacia un anglicanismo mucho más liberal y progresista, para finalmente desembocar en el cristianismo antidogmático y racionalista de los unitarios - aparece como un periplo disparatado y sin sentido, propio de un hombre sin capacidad de creer, que no puede someter durante mucho tiempo su ego a una autoridad superior o una verdad trascendente.

Juan Goytisolo acogió con entusiasmo esta interpretación, e incluso la llevó a su extremo, siguiendo en parte los pasos más prudentes de Vicente Llorens e invirtiendo los juicios de valor de Menéndez Pelayo ${ }^{17}$, para hacer del sevillano un mártir laico del relativismo y la duda. Se permite incluso afirmar su convicción de cuál habría sido la siguiente etapa del eterno deambular filosófico de Blanco, si no hubiera muerto antes:

En realidad, su enemiga a todas las Iglesias y sus alegatos a la tolerancia y libertad de pensamiento lo acercaban cada vez más al grupo positivista de Stuart Mill, aunque nunca llegase a romper con los unitarios. Como ha visto muy bien $\mathrm{Vi}$ cente Llorens, Blanco no podía hallar la tranquilidad en ninguna de las moradas que sucesivamente buscara (Goytisolo, 1982: 55).

Generalizando las conclusiones, Blanco queda asociado con la moderna angustia existencial del siglo XX, la de la falta de respuestas y de verdades. Es decir, puede asociarla a «todos nosotros», y también a él mismo: «la trayectoria religiosa de Blanco White es el resultado lógico de su inquietud y no desemboca en verdad alguna. Pero, por ello mismo, su lección nos pertenece a todos» (1982: 55). De este modo, está de nuevo formulada la identificación de Goytisolo con Blanco, que se convierte en un precursor de una búsqueda sin objeto, en la que buscar es más importante que encontrar:

La permanente ansiedad que corroe su vida le veda, por fortuna, la tentación de atalayar los errores y faltas pasados investido de los poderes sacrosantos de la Verdad. «En tanto que no bajen ángeles para decidir entre las opiniones diversas de los hombres - dice - cualquiera a quien se le encargue hablar en nombre del cielo no será más que el oráculo de sus propias pasiones y deseos.» En los tres volúmenes de su autobiografía, diario y correspondencia, no se abandona jamás al espejismo de situar la verdad en el momento en que escribe, pues sabe que aquélla se gana día a día, en lucha con los propios errores. Pero la falta de lección es sólo aparente y encierra en resumidas cuentas una lección más profunda: la única conclusión posible de un hombre dotado de espíritu crítico, parece decirnos, es que no puede llegar honestamente a ninguna conclusión (Goytisolo, 1982: 20).

Pero la interpretación de la cita de Blanco es más que discutible: defiende el derecho individual a decidir la Verdad (que significativamente, y

${ }^{17}$ Como afirma Loureiro, «Goytisolo's reading of Blanco White is in fact the perfect negative of Menéndez Pelayo's, since one praises what the other condemns, and both engage in their readings from the height of their respective and opposite passions» (1998: 52). 
a pesar del sarcasmo de Goytisolo, escribe a menudo con una solemne mayúscula), no dice que no exista. Goytisolo proyecta sobre Blanco un relativismo y una duda que le permiten compararlo con Unamuno - aunque sin su narcisismo- asegurando que «un perenne desasosiego, hijo de la continua rebelión del espíritu crítico contra la fe cristiana, impregna vida y obra de ambos escritores [...]. Uno y otro vivieron intensamente el dilema de la razón o la fe y, para los dos, el triunfo momentáneo de la primera fue siempre angustioso y pírrico» (1982: 15). Pero eso es no comprender que la base de las ideas de Blanco a partir de su conversión religiosa en Inglaterra es la fe, y que desde entonces nunca la pone en duda, aunque se hace muy exigente al exigir criterios para definir una verdad como tal y discute el derecho a imponerla.

Blanco White escribió en el primer número de su periódico Variedades uno de los más emotivos y convincentes elogios de la duda como principio de conocimiento y como liberación de la mente racional, que desvela la profunda raíz ilustrada de su forma de pensar:

La $D u d a$ es el verdadero principio del saber; la $D u d a$ es el único instrumento que puede destruir montes de errores, poco a poco y sin explosión; la Duda es el único antídoto contra la persecución y la intolerancia. Mas, al hablar de la Duda con tanto elogio no queremos de modo alguno recomendar un necio dudar de todo, que pronto se convierte en un espíritu de contradicción más cabezudo y pertinaz que cuantos doctores chinos o europeos se creen infalibles, los unos a título de las uñas largas que los distinguen de las demás clases, los otros de las borlas que les cuelgan del bonete. Hablamos sólo de la Duda prudente y modesta que pone al ánimo en estado de examinar las cosas, sin cerrar la entrada al convencimiento, ya venga de una, ya venga de otra parte. Hablamos de la Duda que no da por sentado que cuanto se ha tenido por verdadero en tiempos en que dominaba la tiranía civil y religiosa, debe, por necesidad, ser falso. No, por cierto: esto no sería duda, sino decidir a ojos cerrados (Variedades o el Mensajero de Londres, $\mathrm{n}^{\circ}$ 1, 1-I-1823, pp. 51-52).

El elogio de la duda no es un elogio de la incertidumbre. Para él el cuestionamiento de las ideas recibidas es la vía para acceder a la verdad, un sapere aude, no una meta en sí mismo. No desconfiaba de la existencia de verdades absolutas, pero dejó que su razón se liberase del cúmulo de verdades aparentes proclamadas por el poder, así como de las corrupciones e intereses adheridos espuriamente a esas verdades. Al pasaje que acabo de citar le sigue una larga parrafada con las cosas que, según él, no admiten duda: que el universo es obra de un ser inteligente que procura la felicidad de los seres humanos; que el bien de la mayoría se extiende directa o indirectamente al bien de los individuos; que la bondad de corazón, la beneficencia y la verdadera caridad cristiana «llevan grabado en la frente un carácter de verdad y utilidad general que sólo un alma depravada podrá desconocer» (ibíd., p. 52). El terreno de lo opinable más allá de esas verdades es enorme y está enteramente disponible para la libre discusión racional: 
Pero donde quiera que las gentes hayan estado privadas, por siglos, del derecho de pensar, examinar y decidir en puntos que a cada cual le toca averiguar si son verdad o mentira, dudad, amigos, les diremos; mas dudad con moderación y no decidáis ni apasionados, ni de priesa. En fin, tened siempre en memoria que una certeza ciega es por lo común indicio de falsedad (ibíd., p. 53).

Y, cerrando el círculo, una de las últimas cartas que dictó, en marzo de 1841, poco antes de morir, dice lo siguiente sobre las controversias religiosas en que participó: "God alone knows who is in the right. But although this expression sounds like doubt, it does not mean it» (Blanco White, 1845: III, 304).

\section{3) Blanco White, pensador negativo}

Casi al final de su «Presentación crítica», Goytisolo ofrece otra de las claves de su parcial y deformante recuperación de Blanco White:

La nostalgia de lo que pudo ser y no ha sido ha conducido a algunos de los españoles más lúcidos a enfrentarse con la historia de su propio país y a afirmar su propio destino en oposición a aquella. Eso fue lo que, a su manera, hizo Blanco, y sus paisanos de ahora deberíamos agradecérselo. [...]

Llegados a este punto, me atreveré a adelantar una proposición fundada en mi experiencia personal: el escritor debería liberarse de todo aquello que le identifica y define, le da una etiqueta y le fabrica una máscara; o, por mejor decir, debería definirse negativamente, en contraposición a las «esencias» y mitos de su propio país (Goytisolo, 1982: 97).

En efecto, en coincidencia con lo señalado en el punto anterior, la estrategia identificadora de Goytisolo para con Blanco pasa necesariamente por buscar esa identidad en lo que se niega y no en lo que se afirma. Es la forma más directa de ponerse de acuerdo. En ese sentido, ha reivindicado un Blanco White esencialmente negativo ${ }^{18}$, ha recuperado al implacable crítico de la España tradicional, de la Iglesia, de la Inquisición, de las costumbres, de las Cortes de Cádiz, etc. Los ataques del sevillano y su lucidez a la hora de diseccionar los males de nuestra sociedad son la base de la admiración que siente Goytisolo - y que han sentido todos los lectores de Blanco en las últimas décadas- por el escritor de Sevilla. En cambio, el lado carismático de la teología de Blanco, el que afirma en lugar de negar, el que predica la fe en vez de criticar a la Iglesia - a todas las

${ }^{18}$ Con todo, Goytisolo no llega tan lejos en este punto como uno de sus más evidentes seguidores, Eduardo Subirats, que construye toda su interpretación de Blanco White como «el único intelectual filosóficamente consistente del siglo XIX español» (2005: 10) a partir de la idea de que encarna un concepto radical de «modernidad negativa», «conciencia escindida entre su voluntad de reforma y su imposibilidad siquiera de plantearla», «moderno en su construcción de una conciencia exiliada y escindida hasta el extremo de la disociación personal y la esquizofrenia» (14). 
Iglesias finalmente-, el que aspira a la salvación y explora los caminos que cree viables para conseguirla, y para que los cristianos recobren su verdad y su unidad, no interesa, porque no concuerda con las expectativas proyectadas en el personaje y porque obligaría a fijar una distancia, ya que lo que él afirma no es en absoluto lo que su moderno traductor quiere que se afirme. La comunidad atemporal entre ambos, por lo tanto, sólo puede basarse en sostener la vigencia y la actualidad de las críticas negativas de Blanco, y en olvidar el hecho de que también él había formulado una doctrina afirmativa.

Pero en realidad, Blanco y Goytisolo no se parecen casi nada en este punto. Blanco no es ni remotamente un pensador negativo, a pesar de que su pensamiento crítico sea más asequible a nuestra forma de pensar y nos resulte más atrayente y útil. A este respecto, es curioso que la comparación que formula Gonzalo Navajas del «diálogo» que supuestamente establecen Goytisolo y Blanco a través del tiempo, le sirve en realidad para apreciar no una identidad, sino una radical diferencia en sus visiones del mundo: «la desconfianza hacia aproximaciones universales y sistemáticas [...] ocurre en Blanco a partir todavía de los principios de la Aufklärung. Blanco participa de los principios generales de una primera modernidad fundada en el optimismo en torno a las posibilidades de la mente humana. [...] De modo diferencial, Goytisolo no participa en ese optimismo» (Navajas, 2001). Pero lo cierto es que es Navajas el que formula, con acierto, esa distancia, ya que Goytisolo no atribuye a Blanco tal optimismo ni le ve arraigado en la confianza racionalista de la modernidad, con lo cual, una vez más, el vínculo intertemporal entre ambos supuestos dialogantes viene a reducirse a un plano de mera negación: «a pesar de sus diferencias, Goytisolo percibe en Blanco White y Cernuda la realización de la marginación como elemento definitorio de la literatura» (Navajas, 2001).

\section{ESENCIALISMOS}

Todo lo que he venido diciendo hasta aquí de la imagen de Blanco White proyectada por Goytisolo podría predicarse, en realidad, también de otros autores que, con menor o mayor énfasis, ha venido asociando a la tradición de la España disidente. Si se tratara tan sólo de dos escritores aislados, la crítica subyacente a este esquema interpretativo tendría poca fuerza. Goytisolo construye toda una categoría formada por personajes de muchos siglos que comparten una relación semejante de exclusión y de heterodoxia respecto a una España esencialmente intolerante, cainita, tribal y represora, cuya manifestación más constante es el alejamiento físico del disidente, es decir, el exilio. En una entrevista de 1999 le formularon a Juan Goytisolo una pregunta que sólo cabe calificar de retórica: «¿Cree usted 
que hay una línea de escritores españoles exiliados?» Goytisolo contesta con rotundidad que «este fenómeno empieza con el reinado de los Reyes Católicos» y enumera una lista formada por los hermanos Valdés, Vives, Cervantes -exiliado frustrado, pues se le negó ir a América-, Mateo Alemán..., mientras que en el resto de la entrevista asoman aquí y allá Cernuda, Américo Castro, Vicente Llorens, el morisco autor del llamado Kamasutra español, Fernando de Rojas, Blanco White, Alí Bey, etc. (cf. Eilenberger, 1999).

Lo que quiero subrayar es que, en definitiva, el Blanco White deformado por Goytisolo - deformado sólo en parte, por supuesto, no inventado ex novo- no pretende ser sino una ilustración más de la esencia de España o, por decirlo con un término creo que más preciso, del llamado problema de España. Dado que a su juicio el país actual aún no ha superado ese pasado oscuro y sigue mostrando los síntomas del casticismo excluyente, el problema de España no sólo resultaría una forma de ser atemporal, una esencia, sino incluso, al parecer, una esencia eterna e irresoluble. Así, Goytisolo eleva el viejo análisis sobre las dos Españas en su obra literaria y crítica a un plano mítico extraordinariamente intenso y elaborado. A su manera y con singular personalidad, no hace sino amplificar una corriente de pensamiento continuada en todo el siglo XIX y el XX, y sumamente exacerbada por el trauma trágico de la guerra civil y el fracaso de la II República. Los exiliados de 1939 —y los que siguieron sus pasos voluntariamente o a la fuerza en las décadas siguientes, como el propio Juan Goytisolo- recrearon como nadie antes el mito de las dos Españas y lo sintieron no como una idea o un análisis histórico, sino como una vivencia personal dolorosa e imposible de apartar de su memoria. En el exilio interior escribía en los años sesenta Jaime Gil de Biedma unos versos que definen perfectamente esta concepción pesimista y trágica de la identidad española:

\footnotetext{
De todas las historias de la Historia la más triste sin duda es la de España porque termina mal. [...].
}

No obstante, Gil de Biedma no se recrea en el esencialismo e invoca el poder de la historia - de las circunstancias históricas concretas fruto de la voluntad de los hombres y de su capacidad de transformarlas- sobre las presuntas eternidades:

\footnotetext{
Quiero creer que nuestro mal gobierno es un vulgar negocio de los hombres y no una metafísica, que España puede y debe salir de la pobreza, que es tiempo aún para cambiar su historia antes que se la lleven los demonios.
} 
Hay en esos versos una voluntad de superar el problema de España por la vía precisamente de no considerarlo una metafísica, una esencia atemporal que define a una nación a lo largo de los siglos, sino un «vulgar negocio de los hombres», una contingencia. Creo también que, a pesar de algunas apariencias en contrario, esa era también la convicción de Blanco White. Alguien que tenga ese punto de vista no podría sostener que existe una continuidad entre los exiliados de unos siglos y de otros, entre los disidentes religiosos del XVI, los políticos liberales del XIX o los revolucionarios sociales del $\mathrm{XX}$, entre otros muchos. La única manera de buscar en ellos esa identidad, de crear esa tradición, es ver el exilio y la propia disidencia como algo esencialmente negativo, como un enfrentarse a algo, sin importar demasiado a qué ni por qué ni con qué fines. Y de paso, para que el sistema funcione, es preciso ignorar que no todos los exilios españoles son progresistas: a Goytisolo - y a otros muchos - nunca se le ocurre mencionar entre sus precursores a los miles de jesuitas expulsados en 1767 o la emigración política de los carlistas en el XIX.

Esta dialéctica de las dos Españas y esta visión trágica y esencialista del problema nacional no es, por supuesto, original de Goytisolo, sino que está muy presente en la cultura española de los dos últimos siglos y, por desgracia, sigue bastante viva en las visiones sobre estos temas que se siguen produciendo. Pero sí hay un enfoque muy original de Goytisolo en esto y es que su mitificación de las dos Españas le ha llevado a reducir a su mínima expresión la España crítica y progresista, que según él quedaría comprendida únicamente en un puñado de individuos lúcidos y heroicos salpicados en el curso de varios siglos. Su España intolerante es inmensa, enorme, mientras que su España progresista es tan pequeña, tan pequeña, que acaba por concentrarse en Cervantes, en Blanco White, en Larra, en Cernuda, en Américo Castro... Pero después de ver cómo Goytisolo maneja la imagen de Blanco White para asimilarla a la suya propia, resulta que todas esas figuras del pasado vienen a ser la misma; dicho de otro modo, al final la España alternativa reduce peligrosamente su aspecto al de Juan Goytisolo.

En la entrevista que le hizo la revista Espéculo en 1999 le preguntaron, tras haber este glosado la importancia de los autores apátridas y heterodoxos en la literatura española: «Entonces, se puede decir que la distancia del exilio constituye la condición de la posibilidad de su obra narrativa», a lo que Goytisolo responde que «en mi caso concreto, sí» (en Eilenberger, 1999). Pero el novelista catalán nunca se ha quedado en su caso concreto, sino que lo ha elevado a categoría. Por conclusión, citaré otra vez a Antonio Muñoz Molina:

A los escritores, en las mesas redondas o en las entrevistas, les entra a veces un curioso afán legislador: explican que la literatura ha de ser de una cierta manera 
y no de otra y apelan para demostrarlo al ejemplo de algunos grandes nombres, que casualmente son los modelos que a ellos los inspiran. No te engañes, me avisa la presencia querida: cuando un escritor dice admirar mucho a un maestro lo que está haciendo es admirarse y vindicarse por su mediación a sí mismo; ¿no te has dado cuenta de que sólo admiran a los que creen parecerse? («El integrado, el apocalíptico», El País-Babelia, 7-VI-2008).

Ahora bien, Blanco White no es un gran nombre de la literatura y el público culto español desconocía casi por completo su existencia antes de que Goytisolo empezara a promocionarlo. De hecho, es hoy mucho más conocido que leído. La coartada historicista curiosamente ha operado en sentido inverso: es el escritor famoso el que se escuda en el escritor olvidado para crearse una genealogía intelectual autovindicatoria. En este paseo a través de los espejos deformantes del callejón del Gato, se ha perdido buena parte de la imagen real de la obra y del ejemplo del exiliado sevillano. Juan Goytisolo ha construido lo principal de la máscara con que hoy se reconoce a José María Blanco White y esa máscara, no nos engañemos, reproduce los rasgos de Juan Goytisolo. ¿Qué habría pensado el sevillano de todo esto? Con esa duda cierra Martin Murphy su excelente biografía de Blanco, una duda llena de fina ironía británica:

Goytisolo's essay is a brilliant piece of iconoclastic special pleading. «In speaking of Blanco White», he admitted, «I have been speaking of myself.» Nevertheless, his Blanco White caught the imagination of a generation of intellectuals looking for an alternative model of Spanish society. The Blanco White who championed toleration and pluralism was a leading candidate for a new canon of heterodox saints. So his rehabilitation gathered pace. [...] What the man himself would have thought of these attentions, and attendant distortions, is a matter of speculation. He might have felt more at home with Marcelino Menéndez y Pelayo, on the principle that the old enemy offers at least the comfort of familiarity (Murphy, 1989: 204).

Eso, en cualquier caso, no lo podemos saber, pero sí podemos leer a Blanco White y sacar, sin intermediarios, nuestras propias conclusiones.

\section{REFERENCIAS BIBLIOGRÁFICAS ${ }^{19}$}

BLANCO WHITE, Joseph. The Life of the Rev. Joseph Blanco White, written by himself, with portions of his correspondence. John Chapman: Londres, 1845. 3 vols.

DURÁN LÓPEZ, Fernando. José María Blanco White, o la conciencia errante. Sevilla: Fundación José Manuel Lara, 2005, 646 pp. Colección Biografías.

-. «Ideas que imprimen carácter: narración, retrato y otras maniobras de distracción en la Historia de los Heterodoxos». Boletín de la Biblioteca de Menéndez Pelayo. 2006, t. 82, pp. 353-391.

${ }^{19}$ Las fuentes hemerográficas citadas se recogen en las notas a pie de página. 
—. «Blanco y Quintana». Ínsula. Revista de letras y ciencias humanas, 2008, n. ${ }^{\circ} 744$, pp. 17-21.

—. «Blanco White aconseja a los americanos. Variedades o el Mensajero de Londres». En: CASCALES RAMOS, Antonio (coord.). Blanco White, el rebelde ilustrado. Sevilla: Centro de Estudios Andaluces - Facultad de Comunicación de la Universidad de Sevilla, 2009, pp. 53-92.

EILENBERGER, Wolfram; ÁSTVALDSSON, Haukur; HERRERA, Francisco. «Nacionalidad cervantina. Una entrevista con Juan Goytisolo». Espéculo. Revista electrónica cuatrimestral de Estudios Literarios. [en línea]. 1999, n. ${ }^{\circ} 11$ (marzo-junio). [Fecha de consulta 12-03-2010]. Disponible en internet: <http://www.ucm.es/info/especulo/numero11/jgoytiso.html>.

FERNÁNDEZ, James D. «Los matices americanos de Blanco White». En: SUBIRATS, E. (ed.). José María Blanco White: crítica y exilio. Barcelona: Anthropos, 2005, pp. 117125 .

FERNÁNDEZ CIFUENTES, Luis. «Las autobiografías de Blanco White: tres divergencias». En: SUBIRATS, E. (ed.). José María Blanco White: crítica y exilio. Barcelona: Anthropos, 2005, pp. 25-67.

FORMENT, Albert. José Martínez: la epopeya de Ruedo ibérico. Barcelona: Anagrama, 2000 .

GIMFERRER, Pere. «Diálogo de heterodoxos: de Blanco White a Molinos». En Radicalidades. Península: Barcelona, 2000, pp. 187-194.

GOYTISOLO, Juan. «Presentación crítica» a: José María Blanco White. Obra inglesa, selecta de sus obras en esta lengua. Barcelona: Seix Barral, 1982, pp. 1-9820.

—. «Un escritor marginado: Blanco White y la desmemoria española». En: SUBIRAT, E. (ed.). José María Blanco White: crítica y exilio. Barcelona: Anthropos, 2005, pp. 19-24.

LOUREIRO, Ángel G. «Intertextual Lives: Blanco White and Juan Goytisolo». En: BROWNLOW, Jeanne Pl. y KRONIK, John W. (eds.). Intertextual pursuits. Literary mediations in Modern Spanish Literature. Lewisburg - Londres: Bucknell University Press Associated University Presses, 1998, pp. 42-56.

MERCADIER, Guy. «Juan Goytisolo et Blanco White: partage d'exil». En: MOUILLANDFRAISSE, Geneviève; FERNÁNDEZ CARDO, José María (eds.). Littérature et double culture/Literatura y doble cultura. Calaceite: Associations Noésis, 1989. pp. 209-223.

MORENO ALONSO, Manuel. «Sobre la recuperación de Blanco White en España. (Del olvido y del oprobio al descubrimiento y a la admiración)». En: MORENO, ALONSO, Manuel (ed.). José María Blanco White y el problema de la intolerancia en España. Caja San Fernando: Sevilla, 2002, pp. 133-152.

MURPHY, Martin. Blanco White, self-banished Spaniard. New Haven-Londres: Yale University Press, 1989.

NAVAJAS, Gonzalo. «La narración como lectura en Juan Goytisolo». Rencontre avec Juan Goytisolo. En: BUSSIÈRE, Annie (ed.). [en línea]. Montpellier: Université Paul Valéry, 2001, pp. 231-248. En Web: http://www.cervantesvirtual.com/servlet/SirveObras/ 12698309924505940210435/p0000001.htm.

PONS, André. Blanco White y España. Oviedo: Instituto Feijoo de Estudios del siglo XVIII, 2002.

RIBEIRO DE MENEZES, Alison. «Ventriloquism and double-voiced discourse in Juan Goytisolo's literary criticism: the case of José María Blanco White». En: BLACK, Stanley (ed.). Juan Goytisolo: territories of life and writing. Oxford - Berna: Peter Lang, 2007, pp. 77-93.

${ }^{20}$ La primera edición es de Ediciones Formentor, Buenos Aires 1972; Seix Barral la volvió a editar en 1974 y yo manejo aquí la segunda reimpresión de esa edición, de 1982. 
RUIZ LAGOS, Manuel (ed.). Juan Goytisolo. Madrid: Ediciones de Cultura Hispánica, 1991. En la transcripción de las sesiones (pp. 25-99) se incluyen intervenciones orales de Roberto Yahni y de Juan Goytisolo sobre Blanco White.

SARRÍA BUIL, Aránzazu. «Encuentro con Juan Goytisolo». Migraciones \& Exilios. Cuadernos de la Asociación para el estudio de los exilios y migraciones ibéricos contemporáneos. 2002, n. ${ }^{\circ}$ 3, pp. 171-189. (Se transcribe una entrevista en 1999 sobre su relación con Ruedo Ibérico; también en Web: http://www.ruedoiberico.org, por donde cito).

—. «Libre (1971-1972), más allá del exilio español». En: DESVOIS, Jean-Miche (ed.). Prensa, impresos, lectura en el mundo hispánico contemporáneo. Homenaje a JeanFrançois Botrel. Burdeos: Université Michel de Montaigne, 2005, pp. 475-488.

SUBIRATS, Eduardo (2005). «Introducción». En: SUBIRATS, E. (ed.). José María Blanco White: crítica y exilio. Barcelona: Anthropos, pp. 7-17.

URDA ANGUITA, Juan Antonio de. «Foucault y el cuerpo de Blanco White». Dieciocho. Hispanic Enlightenment, 2007, vol. 30, n. ${ }^{\circ}$ 2, pp. 303-314.

Fecha de recepción: 12 de diciembre de 2008

Fecha de aceptación: 26 de mayo de 2009 